\title{
NEW EDITIONS.
}

Clinical Memoranda for General Practitioners. By Alex. Theodore Brand, M.D., C.M., V.D., and John Robert Keith, M.A., M.D., C.M. Second Edition. London : Baillière, Tindall \& Cox. 1923. (7s. 6d. net.)

THE authors, obviously experienced practitioners, have set forth in short articles and paragraphs the fruits of their clinical work. General medicine, surgery, obstetrics, and many of the special branches of work receive attention. The hints and suggestions are thoroughly practical, and embody partly the authors' own views, and partly ideas collected from unany papers and journals. The section on drugs attracts us. It gives helpful advice on the usage of many common remedies. The aphorisms we distrust so newhat-probably on principle. The index should facilitate ready reference for the busy practitioner, to whom this volume should definitely appeal.

A Manual of the Practice of Medicine. By A. A. Stevens, A.M., M.D., Philadelphia. Eleventh Edition. London: W. B. Saunders Company. 1923. (18s. net.)

THE present edition of this Manual, which was first published in 1892, contains much new work. The sections on chronic family jaundice, botulism, epidemic encephalitis, subacute combined sclerosis of the spinal cord, and many others, have been entirely rewritten. In the section dealing with diabetes mellitus much more attention is paid to the "Allen" treatment than to that by insulin. The various diseases are treated in a clear and simple manner, which should appeal to the student. We do not, however, think that it possesses any advantages over other books of a similar nature published in this country.

Clinical Electrocardiography. By Sir Thomas Lewis, M.D., F.R.S., D.Sc., F.R.C.P., C.B.E. Third Edition. London: Shaw \& Sons, Limited. 1924. (8s. 6d. net.)

For anyone who wishes to be able to analyse electrocardiograms no better book could be suggested. The general principles underlying the electrical methods of determining defects in cardiac function are explained in a manner which is both accurate and lucid. Thereafter 